\title{
DESAIN KONTEN PROMOSI DAN SOSIALISASI ORGANISASI MASYARAKAT
}

\author{
Ahmad Zamsuri' ${ }^{1)}$, Wenni Syafitri' ${ }^{2}$, Bayu Febriadi ${ }^{3)}$ \\ 1,2,3) Universitas Lancang Kuning \\ E-mail:wenni20@gmail.com
}

\begin{abstract}
ABSTRAK
Salimah (Persaudaraan Muslimah) berdiri sejak tahun 2000 dengan mengusung 18 Pimpinan Wilayah. Salimah mengusung visi "Menjadi ormas perempuan yang kokoh dan dinamis dalam meningkatkan kualitas hidup perempuan, anak dan keluarga Indonesia “. Salimah juga aktif melakukan komunikasi seperti berbagi ataupun sharing ilmu pengetahuan menggunakan sarana media sosial. Kegiatan pengabdian ini fokus kepada salah satu pimpinan wilayah, yaitu Riau. Salimah Riau menggunakan website ataupun social media sebagai media Penyampaian informasi. Desain kontent informasi yang ada saat ini masih bersifat kurang informatif. Penyampaian informasi yang efektif akan memberikan nilai tambah serta meningkatkan minat bagi audiensi. Solusi yang ditawarkan kepada mitra adalah melakukan pelatihan desain konten dengan harapan mampu mendapatkan tingkat audiensi yang tinggi ketika dilakukan implementasi di masyarakat. Kegiatan ini dilaksanakan pada tanggal 25 Januari 2020 bertempat di DILo Pekanbaru. Kegiatan ini diikuti oleh 23 peserta yang berasal dari masing-masing kabupaten di Riau. Peserta terdiri masing-masing perwakilan kabupaten. Peserta sangat antusias untuk mengikuti kegiatan ini. Kami juga melakukan evaluasi terhadap kegiatan ini menggunakan nilai ambang batas CR dan CS. Hasil evaluasi kami menunjukkan bahwa kegiatan ini telah berhasil memenuhi target. Nilai CS dan CR untuk pre-test dan post-test adalah 1.
\end{abstract}

Kata kunci: Desain Konten, Organisasi Masyarakat, Teknologi Informasi

\section{ABSTRACT}

Salimah (Persaudaraan Muslimah) was established in 2000 with 18 Regional Leaders. Salimah carries the vision of "Being a strong and dynamic women's mass organization in improving the quality of life of women, children, and Indonesian families." Salimah also actively communicates such as sharing or sharing knowledge using social media. This community service focus is on one of the regional leaders, namely Riau. Salimah Riau uses website or social media as a medium for delivering information. The design of the current content of the information is still not very informative. Effective delivery of information will provide added value and increase interest in the audience. The solution offered to partners is to conduct content design training in the hope of being able to get a high level of the audience when implemented in the community. This activity was carried out on January 25, 2020, at DILo Pekanbaru. This activity was attended by 23 participants from each district in Riau. The participants consisted of each district representative. The participants were very enthusiastic about participating in this activity. We also evaluated this activity using CR and CS threshold values. Our evaluation results show that this activity has successfully met the target. CS and CR values for pre-test and post-test are 1. Key words: Content Design, Information Technology, Community Organizations 


\section{PENDAHULUAN}

Organisasi Masyarakat Salimah (Persaudaraan Muslimah) berdiri sejak tahun 2000 dengan mengusung 18 Pimpinan Wilayah. Salimah mengusung visi "Menjadi ormas perempuan yang kokoh dan dinamis dalam meningkatkan kualitas hidup perempuan, anak dan keluarga Indonesia “. Sehingga salimah memiliki misi yang harus dicapai demi terwujudnya visi yaitu:

1. Memperluas wilayah dan memperkokoh soliditas struktur.

2. Meningkatkan kualitas pengurus dan anggota agar mampu merealisasikan visi dan misi Salimah.

3. Meningkatkan kuantitas anggota sebagai basis massa Salimah.

4. Meningkatkan peran serta Salimah dalam upaya peningkatan kualitas perempuan, perlindungan anak dan pengokohan keluarga.

5. Meluaskan dan mengokohkan kemitraan dengan pemerintah dan lembaga lain dalam merealisasikan program yang terkait isu perempuan, anak dan keluarga.

6. Mengokohkan peran dan posisi Salimah dalam peta pergerakan perempuan Indonesia.

Salimah juga aktif melakukan komunikasi seperti berbagi ataupun sharing ilmu pengetahuan menggunakan sarana media sosial. Sabil (Salimah Berbagi Ilmu secara Online) sebagai program komunikasi yang mengusulkan tema pembahasan seputar Pendidikan, Syariah dan bisnis. Program Sabil ini memiliki anggota tidak hanya di Indonesia namun juga ada di luar negeri, seperti Australia, Arab Saudi, Amerika dan lainnya. Salimah juga mendirikan PT. SPC (Salimah Prima Cita) yang bertugas memasarkan makanan olahan beku. Salimah juga berperan aktif pada kegiatan sosial kemanusiaan seperti program pembinaan anak yatim (P2AY) meliputi bantuan finansial pendidikan dan pembinaan pribadi secara berkala dengan nama TRAY (Taklim Rutin Anak Yatim) dan Pos Penanggulangan Musibah dan Bencana (P2MB).

Kegiatan pengabdian ini fokus kepada salah satu pimpinan wilayah, yaitu Riau. Salimah Riau dipimpin oleh Kasmidar Kanin, S. Pd. Salimah Riau memiliki 6 Departemen yaitu Dakwah, Pendidikan, Humas, SDM, Bangda dan Ekonomi.

Penyampaian informasi pada PW salimah dapat berupa website ataupun social media. Desain content informasi yang ada saat ini masih bersifat kurang informatif. Penyampaian informasi yang efektif akan memberikan nilai tambah serta meningkatkan minat bagi audiensi.

\section{TINJAUAN PUSTAKA}

Kegiatan ini bekerja sama dengan mitra yaitu Pimpinan Wilayah Riau Salimah, dengan target kegiatan yaitu dapat menggunakan keahlian yang diperoleh pada pelatihan untuk pengembangan desain konten. Konten informasi yang informatif akan memberikan banyak keuntungan salah satunya keberlangsungan hubungan antara konsumen dan produsen.

Desain konten memiliki pengaruh yang berbeda terhadap target konsumen (Shareef et al., 2017). Hal ini disebabkan oleh gaya hidup konsumen, kepribadian, dan sifat-sifat yang kompatibel dengan desain konten yang mempertimbangkan kata-kata, bahasa, presentasi, organisasi, dan struktur konten. Desain informasi sebaiknya memberikan kemudahan dan pemahaman terhadap pengguna(Hasan, 2016). Framing terhadap informasi juga memberikan 
pengaruh terhadap audiensi (Strekalova and Damiani, 2018). (Lee, 2018) mengatakan bahwa kombinasi menggunakan karakteristik informasi dengan personal brand dari produk akan meningkatkan kedekatan dengan konsumen.

Pelanggan dan pengguna memiliki peran dan kontribusi efektif terhadap desain dan pengembangan produk (Rathore, Ilavarasan and Dwivedi, 2016). Perbedaan gender juga dapat mempengaruhi model informasi yang akan diberikan, misalnya desain konten ringkas dan visual yang menarik bagi pria, sedangkan bagi wanita cukup diberikan model informasi verbal dan berbasis teks (Shaouf, Lü and Li, 2016) sehingga wanita lebih cenderung mendapatkan informasi yang lebih (Verhellen, Dens and de Pelsmacker, 2016). Namun hal yang paling penting adalah konten dari informasi tersebut (Kim, Choi and Kim, 2019), selain dari faktor jangkauan, frekuensi dan waktu (Ott et al., 2016; Sahni, Wheeler and Chintagunta, 2018).

Kebutuhan terhadap kegiatan ini sebagai berikut:

\section{A. Mitra}

Peserta berasal dari Pimpinan Salimah Wilayah Riau, dengan minimal 5 orang yang terdiri dari anggota pada PW Salimah Riau. Peserta diharapkan mampu membuat dan merancang konten informasi. Minimal luaran yang diharapkan dari kegiatan ini adalah:

- Mampu memahami dasar perancangan konten informasi.

- Mampu mengembankan konsep yang telah dipelajari sesuai dengan kebutuhan organisasi.

B. Keberhasilan pelaksanaan kegiatan

Penilaian kegiatan ini sebagai berikut:

- Tingkat kehadiran peserta minimal $90 \%$.

- Kegiatan pelatihan telah dilaksanakan.

- Minimal 80\% mampu menguasai perancangan konten informasi.

- Terciptanya pengembangan desain konten informasi sesuai kebutuhan organisasi.

\section{METODE PELAKSANAAN}

\section{Pendahuluan}

PW salimah saat ini belum menghasilkan desain konten yang optimal kepada anggota ataupun masyarakat. Perancangan konten sebatas informasi yang seperlunya sahaja. Sehingga target audiensi belum dapat dioptimalkan.

\section{Pendekatan Solusi}

Solusi yang diberikan adalah pelatihan desain konten yang menarik dan informatif, sehingga masyarakat lebih tertarik dan banyak memberikan masukan yang dapat mengembangkan organisasi.

\section{Prosedur Kerja}

Prosedur kerja pada kegiatan ini sebagai berikut:

A. Mengajukan permohonan kegiatan kepada LPPM Unilak

B. Finalisasi terhadap administrasi kegiatan.

C. Menghantarkan surat kesedian kerjasama kepada Pimpinan Salimah Wilayah Riau. 
D. Menghantarkan undangan kepada Pimpinan Salimah Wilayah Riau supaya mengirimkan utusan minimal 5 orang.

E. Mempersiapkan modul pelatihan desain konten.

F. Sosialisasi dan pelatihan desain konten.

G. Evaluasi pelaksanaan kegiatan

\section{Rencana Kegiatan}

Pelaksanaan kegiatan ini akan membutuhkan waktu selama 3 jam dengan rincian sebagai berikut:

Pukul 10.00-11.00 (Pengenalan Desain Konten)

Pukul 11.00-13.00 (Workshop Desain Konten).

\section{HASIL DAN PEMBAHASAN}

Kegiatan ini telah berhasil dilaksanakan pada tanggal 25 Januari 2020 di DILo Pekanbaru. Berikut rincian kegiatan yang telah dilaksanakan:

\section{Sosialisasi}

Salimah merupakan sebuah ormas yang fokus kepada pemberdayaan perempuan. Beberapa aktivitas yang dilakukan untuk meningkatkan kesejahteraan perempuan. Seperti melakukan kegiatan workshop ataupun seminar. Pada kesempatan ini, kami memberikan workshop pada Salimah dengan topik mengenai desain konten promosi dan sosialisasi. Kegiatan ini sangat bermanfaat sekali menurut Salimah, mengingat topik kegiatan memiliki keterkaitan dengan visi dan misi Salimah.

Salimah memerlukan kegiatan desain konten, terutama untuk meningkatkan kualitas konten dan promosi Salimah. Oleh karena itu kami memberikan pelatihan tersebut agar dapat memenuhi ekspektasi tersebut.

\section{Pelatihan}

Kegiatan ini telah berhasil dilaksanakan pada tanggal 25 Januari 2020. Kegiatan yang dilaksanakan adalah workshop desain konten promosi dan sosialisasi. Kami selalu memastikan bahwa kegiatan ini dapat memenuhi target, salah satunya dengan menggunakan kuisioner. Kuisioner diberikan pada awal sebelum mulai pelatihan dan setelah melaksanakan pelatihan. Jumlah pertanyaan bersifat ya dan tidak, sehingga memudahkan mendapatkan informasi dari peserta. Jumlah pertanyaan yaitu 7 butir pertanyaan untuk setiap periode (pretest dan post-test). Semua hasil periode pertanyaan kami olah menggunakan konsep nilai ambang batas koefisien Reprodusibilitas (CR) dan Skalabilitas (CS) (Howell, 2010). Konsep tersebut sebagai salah satu jaminan bahwa kegiatan pengabdian kami dapat memenuhi target.

\section{. Koefisien Reprodusibilitas (CR)}

CR merupakan pengukuran kehandalan terhadap hasil kuisioner dengan nilai ambang batas yaitu $\geq 0.90$ (Howell, 2010).

.Rumus:

Keterangan:

$$
C R=1-\left(\frac{T E}{P E}\right)
$$

$\mathrm{TE}=$ Jumlah eror 
$\mathrm{PE}=$ Jumlah eror yang kemungkinan terjadi.

\section{Koefisien Skalabilitas (CS)}

Nilai CS diperhatikan jika nilai CR mengalami penyimpangan dengan batas yang dapat diizinkan yaitu $\geq 0.60$ (Howell, 2010).

Keterangan:

$$
C S=1-\left[\frac{T E}{T E x Z}\right]
$$

$\mathrm{TE}=$ Jumlah eror

$\mathrm{Z}=$ Jumlah Kesalahan yang diterapkan

$\mathrm{Tn}=$ Jumlah Pilihan Jawaban

Berikut hasil penilaian kegiatan pengabdian masyarakat berdasarkan kuisioner PreTest dan Post-Test. Nilai $2=$ tidak dan nilai $1=$ ya.

Tabel 1. Hasil Pre-Test

\begin{tabular}{l|lllllllll}
\hline $\boldsymbol{R E S P O N D E N}$ & VA1 & VA2 & VA3 & VA4 & VA5 & VA6 & VA7 & Total & Error \\
\hline $\mathbf{1}$ & 2 & 2 & 2 & 2 & 2 & 2 & 2 & 14 & 0 \\
$\mathbf{2}$ & 2 & 2 & 2 & 2 & 2 & 2 & 2 & 14 & 0 \\
$\mathbf{3}$ & 1 & 2 & 2 & 2 & 2 & 1 & 1 & 11 & 0 \\
$\mathbf{4}$ & 2 & 2 & 2 & 2 & 2 & 2 & 2 & 14 & 0 \\
$\mathbf{5}$ & 2 & 2 & 2 & 2 & 2 & 2 & 2 & 14 & 0 \\
$\mathbf{6}$ & 2 & 2 & 2 & 2 & 2 & 2 & 2 & 14 & 0 \\
$\mathbf{7}$ & 1 & 2 & 2 & 2 & 1 & 1 & 1 & 10 & 0 \\
$\mathbf{8}$ & 2 & 2 & 2 & 2 & 2 & 2 & 2 & 14 & 0 \\
$\mathbf{9}$ & 2 & 2 & 2 & 2 & 2 & 2 & 2 & 14 & 0 \\
$\mathbf{1 0}$ & 1 & 2 & 2 & 2 & 1 & 1 & 2 & 11 & 0 \\
$\mathbf{1 1}$ & 2 & 2 & 2 & 2 & 2 & 2 & 2 & 14 & 0 \\
$\mathbf{1 2}$ & 2 & 2 & 2 & 2 & 2 & 2 & 2 & 14 & 0 \\
$\mathbf{1 3}$ & 2 & 2 & 2 & 2 & 2 & 2 & 2 & 14 & 0 \\
$\mathbf{1 4}$ & 2 & 2 & 2 & 2 & 2 & 2 & 2 & 14 & 0 \\
$\mathbf{1 5}$ & 2 & 2 & 2 & 2 & 2 & 2 & 2 & 14 & 0 \\
$\mathbf{1 6}$ & 2 & 2 & 2 & 2 & 2 & 2 & 2 & 14 & 0 \\
$\mathbf{1 7}$ & 2 & 2 & 2 & 2 & 2 & 2 & 2 & 14 & 0 \\
$\mathbf{1 8}$ & 2 & 2 & 2 & 2 & 2 & 2 & 2 & 14 & 0 \\
$\mathbf{1 9}$ & 2 & 2 & 2 & 2 & 2 & 2 & 2 & 14 & 0 \\
$\mathbf{2 0}$ & 1 & 2 & 2 & 1 & 2 & 2 & 2 & 12 & 0 \\
$\mathbf{2 1}$ & 2 & 2 & 2 & 2 & 2 & 2 & 2 & 14 & 0 \\
$\mathbf{2 2}$ & 2 & 2 & 2 & 2 & 2 & 2 & 2 & 14 & 0 \\
$\mathbf{2 3}$ & 2 & 2 & 2 & 2 & 2 & 2 & 2 & 14 & 0 \\
\hline
\end{tabular}




\begin{tabular}{l|ccccccccc}
\hline RESPONDEN & VA1 & VA2 & VA3 & VA4 & VA5 & VA6 & VA7 & Total & Error \\
\hline Jumlah & & & & & & & & 310 & 0 \\
\hline
\end{tabular}

Berdasarkan tabel 1, sebanyak 23 orang telah berhasil menjawab 7 butir pertanyaan pada periode Pre-test. Beberapa responden memiliki beberapa pengetahuan tentang desain konten promosi dan sosialisasi secara umum. Jika kita menggunakan rumus $\mathrm{CR}$ dan $\mathrm{CS}$ diatas untuk penilaian hasil kuisioner pre-test, maka disimpulkan bahwa nilai CR dan CS adalah 1. Kemudian kami melakukan evaluasi setelah pelaksanaan workshop, yaitu post-test. pada tabel 2, dapat disimpulkan nilai CR dan CS adalah 1.

\begin{tabular}{|c|c|c|c|c|c|c|c|c|c|}
\hline RESPON & VA1 & $V A 2$ & $V A 3$ & VA4 & VA5 & VA6 & $V A 7$ & Total & Jumlah Error \\
\hline 1 & 1 & 1 & 1 & 2 & 1 & 2 & 2 & 10 & 0 \\
\hline 2 & 1 & 1 & 1 & 1 & 1 & 1 & 1 & 7 & 0 \\
\hline 3 & 1 & 1 & 1 & 1 & 1 & 1 & 1 & 7 & 0 \\
\hline 4 & 1 & 1 & 1 & 1 & 1 & 1 & 1 & 7 & 0 \\
\hline 5 & 1 & 1 & 1 & 1 & 1 & 1 & 1 & 7 & 0 \\
\hline 6 & 1 & 1 & 1 & 1 & 1 & 1 & 1 & 7 & 0 \\
\hline 7 & 1 & 1 & 1 & 1 & 1 & 1 & 1 & 7 & 0 \\
\hline 8 & 1 & 1 & 1 & 1 & 1 & 1 & 1 & 7 & 0 \\
\hline 9 & 1 & 1 & 1 & 1 & 1 & 1 & 1 & 7 & 0 \\
\hline 10 & 1 & 1 & 1 & 1 & 1 & 1 & 1 & 7 & 0 \\
\hline 11 & 1 & 1 & 1 & 1 & 1 & 1 & 1 & 7 & 0 \\
\hline 12 & 1 & 1 & 1 & 1 & 1 & 1 & 1 & 7 & 0 \\
\hline 13 & 1 & 1 & 1 & 1 & 1 & 1 & 1 & 7 & 0 \\
\hline 14 & 1 & 1 & 1 & 1 & 1 & 1 & 1 & 7 & 0 \\
\hline 15 & 1 & 1 & 1 & 1 & 1 & 1 & 1 & 7 & 0 \\
\hline 16 & 1 & 1 & 1 & 1 & 1 & 1 & 1 & 7 & 0 \\
\hline 17 & 1 & 1 & 1 & 1 & 1 & 1 & 1 & 7 & 0 \\
\hline 18 & 1 & 1 & 1 & 1 & 1 & 1 & 1 & 7 & 0 \\
\hline 19 & 1 & 1 & 1 & 1 & 1 & 1 & 1 & 7 & 0 \\
\hline 20 & 1 & 1 & 1 & 1 & 1 & 1 & 1 & 7 & 0 \\
\hline 21 & 1 & 1 & 1 & 1 & 1 & 1 & 1 & 7 & 0 \\
\hline 22 & 1 & 1 & 1 & 1 & 1 & 1 & 1 & 7 & 0 \\
\hline 23 & 1 & 1 & 1 & 1 & 1 & 1 & 1 & 7 & 0 \\
\hline Jumlah & & & & & & & & 164 & 0 \\
\hline
\end{tabular}

\section{Evaluasi Hasil}

Evaluasi kegiatan menggunakan nilai CS dan CR telah berhasil dilakukan. Nilai CS dan CR untuk periode Pre-test dan Post-test yaitu 1. Hal ini dapat disimpulkan bahwa kegiatan pengabdian kepada masyarakat telah mencapai target. 


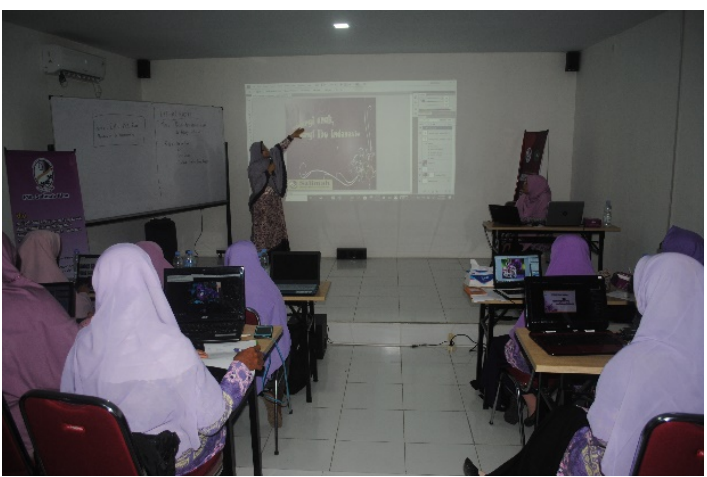

Gambar 1. Kegiatan Workshop Sedang Berlangsung

\section{KESIMPULAN}

Pelaksanaan kegiatan kepada masyarakat penting sekali untuk dilakukan, terutama pada Organisasi Masyarakat. kegiatan ini membantu organisasi masyarakat yaitu Salimah dalam hal melakukan desain konten promosi dan sosialisasi. Kegiatan ini dilaksanakan pada tanggal 25 Januari 2020 bertempat di DILo Pekanbaru. Kegiatan ini diikuti oleh 23 peserta yang berasal dari masing-masing kabupaten di Riau. Peserta terdiri masing-masing perwakilan kabupaten. Peserta sangat antusias untuk mengikuti kegiatan ini. Kami juga melakukan evaluasi terhadap kegiatan ini menggunakan nilai ambang batas CR dan CS. Hasil evaluasi kami menunjukkan bahwa kegiatan ini telah berhasil memenuhi target. Nilai CS dan CR untuk pre-test dan post-test adalah 1.

Saran kegiatan ini selanjutnya adalah melakukan pengembangan materi terhadap desain konten promosi dan sosialisasi, mengingat perkembangan jaman begitu cepat berubah.

\section{DAFTAR PUSTAKA}

[1].Hasan, B. (2016) 'Perceived irritation in online shopping: The impact of website design characteristics', Computers in Human Behavior. Elsevier Ltd, 54, pp. 224 230. doi: 10.1016/j.chb.2015.07.056.

[2].Howell, R. J. (2010) 'The Guttman Approach to Modeling Drug Sequences ',, 6(3), pp. 1-15.

[3].Kim, J., Choi, D. and Kim, H. (2019) 'Advertising nativeness as a function of content and design congruence', International Journal of Advertising. Routledge, 38(6), pp. 845-866. doi: 10.1080/02650487.2018.1535224.

[4].Lee, D. (2018) 'Advertising Content and Consumer Engagement on Social Media : Evidence from Facebook Advertising Content and Consumer Engagement on Social Media':

[5].Ott, H. K. et al. (2016) 'Effect of Message Interactivity on Product Attitudes and Purchase Intentions', Journal of Promotion Management, 22(1), pp. 89-106. doi: 10.1080/10496491.2015.1107011.

[6].Rathore, A. K., Ilavarasan, P. V. and Dwivedi, Y. K. (2016) 'Social media content 
and product co-creation: an emerging paradigm', Journal of Enterprise Information Management, 29(1), pp. 7-18. doi: 10.1108/JEIM-06-2015-0047.

[7]. Sahni, N. S., Wheeler, S. C. and Chintagunta, P. (2018) 'Personalization in Email Marketing: The Role of Noninformative Advertising Content', Marketing Science, 37(2), pp. 236-258. doi: 10.1287/mksc.2017.1066.

[8]. Shaouf, A., Lü, K. and Li, X. (2016) 'The effect of web advertising visual design on online purchase intention: An examination across gender', Computers in Human Behavior. Elsevier Ltd, 60, pp. 622-634. doi: 10.1016/j.chb.2016.02.090.

[9]. Shareef, M. A. et al. (2017) 'Content design of advertisement for consumer exposure: Mobile marketing through short messaging service', International Journal of Information Management, 37(4), pp. 257-268. doi: 10.1016/j.jinfomgt.2017.02.003.

[10]. Strekalova, Y. A. and Damiani, R. E. (2018) 'Message Design and Audience Engagement with Tobacco Prevention Posts on Social Media', Journal of Cancer Education. Journal of Cancer Education, 33(3), pp. 668-672. doi: 10.1007/s13187016-1135-x.

[11]. Verhellen, Y., Dens, N. and de Pelsmacker, P. (2016) 'A longitudinal content analysis of gender role portrayal in Belgian television advertising', Journal of Marketing Communications, 22(2), pp. 170-188. doi: 10.1080/13527266.2013.871321. 